\title{
Social Indicators of Vulnerability to Floods An empirical case study in two Upper Tisza flood basins
}

\author{
Anna Vari (Corresponding author) \\ Hungarian Academy of Sciences \\ Institute of Sociology \\ Uri u. 49 \\ 1014 Budapest, Hungary \\ Tel: +36 1224-6743 \\ Email: anna.vari@socio.mta.hu \\ Zoltan, Ferencz \\ Hungarian Academy of Sciences \\ Institute of Sociology \\ Uri u. 49, \\ 1014 Budapest, Hungary \\ Tel: +36 1 224-6700/417 \\ Email: ferencz@socio.mta.hu \\ Stefan Hochrainer \\ IIASA - International Institute for Applied Systems Analysis \\ Risk and Vulnerability \\ Schlossplatz 1 \\ 2361 Laxenburg, Austria \\ Tel.: +432236 807-517 \\ Email: hochrain@iiasa.ac.at
}

\begin{abstract}
The paper aims to develop indicators of social vulnerability related to flood impacts on the regional level. Impacts are seen here as a function of the exposure as well as the vulnerability dimensions. Because key vulnerability factors include several variables that cannot be found in statistical databases, such as preparedness to the hazard, mental coping capacity, social relations, and trust, an approach based on questionnaire surveys instead of only using statistical data from institutions was chosen. The analysis is based on an empirical survey conducted in the Bodrogköz area and in the Bereg region within the Tisza flood basins. We found that while the most important variables influencing impacts were the exposure level and the geographic location, the most important factors of vulnerability were found to be the following: health, education, savings, opportunities of taking loans, trust in the members of the community and in institutions, and perception of preparedness of institutions against floods. Based on the results we give some policy recommendations with regard to increasing the resilience of the exposed communities. These include, increasing public spending on education, strengthening social cohesion, introducing contingency loans so that borrowing is feasible also for the poorer communities and improving flood preparedness by providing relevant information for inhabitants.
\end{abstract}

Keywords: Vulnerability to Floods, Survey, Case Study, Upper Tisza river basin 


\section{Introduction}

In large parts of Europe, extreme weather events, such as heavy precipitation, wind storms and heat waves, are expected to become more frequent and intense in the future due to climate change (Parry et al. 2007; Alcamo et al. 2007). However, climate-related extremes already put a heavy burden on Europeans at different scales, from households, businesses and governments to the European Union. They differentially affect society depending on geography, as well as the economic, social and cultural context of those exposed, including age, health status, education, income, indebtedness, to name but a few factors contributing to vulnerability (Linnerooth-Bayer et al. 2005). Hence, a better understanding of the complex relationships of these factors will also help to decrease vulnerability against extremes more effectively not only for today but also in the future.

The term "Vulnerability" is nowadays a concept with multiple and ambiguous meanings, used within a broad range of disciplinary contexts, including geography, anthropology, engineering sciences, ecology, and economics. For example, while in the context of climate change, vulnerability is defined as "the degree to which a system is susceptible to, and unable to cope with, adverse effects of climate change, including climate variability and extremes. [...] is a function of the character, magnitude and rate of climate change and the variation to which as system, is exposed, its sensitivity and its adaptive capacity" (IPCC 2007: p.27), in the disaster community vulnerability is defined as "The characteristics and circumstances of a community, system or asset that make it susceptible to the damaging effects of a hazard" (UNISDR 2008: p. 12). Hence, in the later terminology vulnerability is independent of its exposure. To make things even vaguer, in the disaster community it is common to use the notion of vulnerability more broadly and usually vulnerability includes the element's exposure (UNISDR 2008). A more workable definition of vulnerability for this article comes from Turner et al. (2003) which defines vulnerability as the degree to which a system or subsystem is likely to experience harm due to exposure to a hazard, either as a perturbation or stressor. Most importantly in this approach vulnerability incorporates not only exposure but also resilience, now a key concept in vulnerability research, which refers to the capacity of the system to absorb disturbances and reorganise, while undergoing changes to retain essentially the same function, structure, and identity (Walker et al. 2002). Hence, resilience decreases vulnerability.

Still, at this level of complexity it is difficult to carry out any empirical research and focus on some dimensions of vulnerability is necessary. Generally speaking, the different dimensions can be grouped into physical, economical, social and environmental factors as listed below (Kohler et al. 2004):

- Physical: related to the susceptibility to damage of engineering structures such as houses, dams or roads. Also factors such as population growth may be subsumed under this category.

- Social: defined by the ability to cope with impacts on the individual level as well as referring to the existence and robustness of institutions to deal with and respond to natural disaster.

- Economic: refers to the economic or financial capacity to refinance losses and recover quickly to a previously planned economic activity path. This may relate to private individuals as well as companies and the asset base and arrangements, or to governments that often bear a large share of a country's risk and losses.

- Environmental: a function of factors such as land and water use, biodiversity and stability of ecosystems. 
Furthermore, natural disasters may cause a variety of effects which are usually classified into social, economic, and environmental impacts as well as according to whether they are triggered directly by the event or occur over time as indirect effects. In this paper social and economic vulnerability is looked at only, and exposure is treated as a separate variable, both together with vulnerability leading to damages and indirect effects (Figure 1).

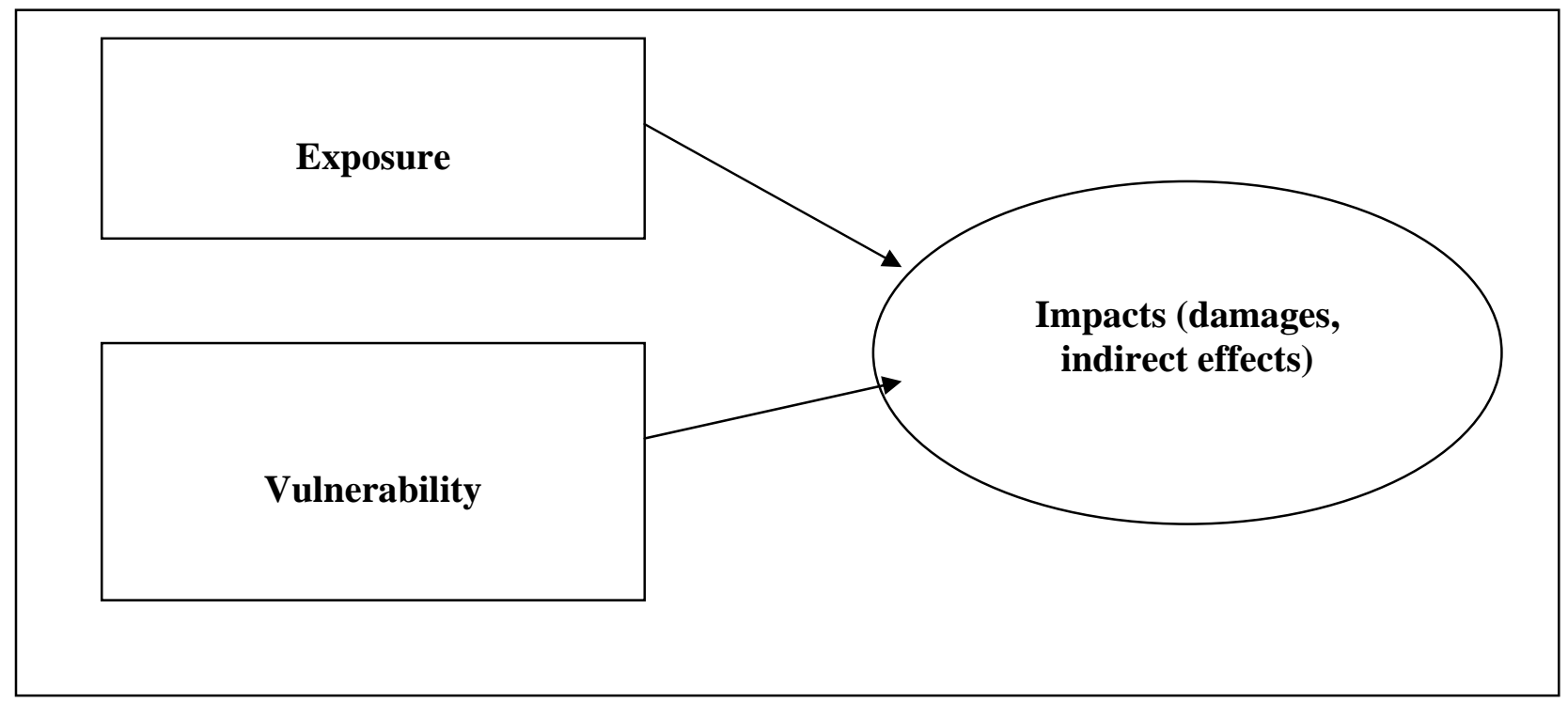

Fig. 1 Exposure to hazard, vulnerability, and impacts

It is a central issue and one of the key goals in the vulnerability research community to find out what factors determine the vulnerability of individuals, communities, organizations and systems, and how vulnerability can be reduced (UNU-EHS 2005). The purpose of this paper is to develop regional indicators of social and economic vulnerability to flood damages in the Upper Tisza region. We hypothesize that many key vulnerability factors cannot be found in statistical databases, such as preparedness to the hazard, mental coping capacity, social relations, and trust, among others. For this reason we use a standardized questionnaire so that these variables can be incorporated within this study design.

The paper is organized as follows: The next section introduces to the problem of the Hungarian floods, than the questionnaire, sampling method and first exploratory results. Section 4 presents the results separated according to bivariate and multivariate relationships found in the statistical analysis of the data. Finally, section 5 ends with a discussion of the results and conclusions.

The background

One of the highest flood risk areas in Hungary is the Upper Tisza river basin in the northeastern part of the country. The intensity and frequency of flood disasters in this region, appear to be increasing because of development and farming practices in the exposed areas, deforestation and other land-use practices, the regulation of the river, and neglect of the drainage systems.

Worsening weather extremes due to climate change may also be a contributing factor. Since 
1998, record breaking water levels of the river have occurred annually, but the extensive network of levees surrounding the river have prevented major losses. The flood of 2001, however, burst through the protective levees and caused extensive damage in the Bereg region.

In Hungary, flood prevention, mitigation, and emergency management has traditionally been the responsibility of the National Water Authority and 12 regional water management directorates. During the state socialist period, the water management authorities established a strong hierarchical system with a staff of approximately 30,000, but after the political transition this system was significantly reduced to approximately 4,000 persons and several tasks (e.g., maintenance of smaller dikes and municipal drainage systems) were assigned to local governments. However, local authorities do not possess sufficient funding and expertise to meet these responsibilities. They are increasingly building on local capacities, especially the skills of their residents.

The principles of flood control development policy - the Vásárhelyi’s Plan Floods are no abnormal events on the Hungarian rivers, they are inherent features of the natural hydrologic regime. Floods have occurred in the past and will occur in the future, Man must adapt himself to them. Floods by themselves spell no disaster, such situations arise in the wake of a failure of the defences and subsequent inundation of the reclaimed flood plain with losses in property and life. On some Hungarian rivers flood levels are liable to rise and the hydrologichydraulic parameters of flood wave travel are liable to change owing to the combined impact of unprecedented extreme hydrometeorological conditions and of human activities in the mountainous, but also in the predominantly flat, Hungarian parts of their catchment. Flood control developments must be implemented in response to the needs of society and geared to the capacity of economy. Efforts must continue at strengthening the main levees, of which no more than $63 \%$ of the main levees meet presently the safety standards (crest height, stability) prescribed. In relation to the recent flood events (1998-2001) in the Tisza basin the attitude of the population has been changed. The floods called the attention to the importance of the safety, as well as to the limitations and the uncertainties of the protection. Therefore the development of new concepts has been driven in the wake of four major floods within a 28 month long period. It become evident that new opportunities of flood defence have to be explored and assessed, they have to be analysed and systemized.

Underlying the majority of early flood control developments had been the desire to reclaim flood plain lands and to raise property values. These aims have played a decisive role in adopting 150 years ago the method of flood control, that is the construction levees, which became by now organic features of the landscape. Changes in attitude have since shifted emphasis in assessing flood damages from crop losses to direct hazards to the population and the destruction of its homes, placing the safety of human existence on the top of the list of priorities.

Interests have changed fundamentally parallel to the re-evaluation of the role of flood control. The total loss of property, especially of their home has become an unacceptable risk to the population exposed to flood hazards and the liability of the state for compensating damages has surmounted the costs of improving flood safety of relatively minor affected areas already.

The paper reports on the mapping and inventory of possible interventions in the Tisza valley in line with the aim to protect people and assets in the area and develop the ecology of Tisza, its tributaries and the floodplain. Possible measures include: 
- storage in the upstream (abroad) part of the catchment

- increasing conveyance capacity of flood bed

- low-land storage

- heightening flood protection levees

Based on this concept the optimal development policy for the Tisza-valley flood protection system is the combination of different technical alternatives providing also an opportunity for the rehabilitation of the Tisza River and the neighbouring landscape. 


\section{Methodology}

\section{Sample}

A face-to-face questionnaire was administered in two high-risk flood basins (Bodrogköz and Bereg) of the Upper Tisza region ${ }^{1}$, with samples of 400 interviewees in 18 villages in the Bodrogköz area and 300 interviewees in 22 villages in the Bereg region. Data collection was conducted in January 2006 in Bodrogköz, and in August 2006 in Bereg. The interviewees were chosen randomly from the population by the demographical quota ${ }^{2}$. This quota ensured representativeness of the population in the sample with respect to gender of the respondents, their age (approximately half of the respondents consisted of adults below 29 years of age and above 60 years of age), and education (most respondents had less than 8 classes of primary school, with Bereg showing a larger amount compared to Bodrogköz) .

\section{Method}

The purpose of the questionnaire was to obtain information from the respondents on their exposure, vulnerability and impacts from previous floods:

- Exposure: The water management authorities classify settlements according to their flood exposure; however, due to differences in elevation there is differential exposure even within one settlement. For this reason, we chose to rely instead on the respondents' self classification of their exposure as part of the questionnaire.

- Vulnerability: We initially hypothesized that flood vulnerability is related both to individual and community preparedness and to social and economic characteristics, such as health, education, economic activity, income, savings, and social capital ${ }^{3}$. As a basis for the questions, we made use of vulnerability indicators found to be relevant in the international literature (for example UNU-EHS 2005), as well as in the findings of our earlier research (Vári and Ferencz 2006)

- Impacts: Only a very small number of people have lost their lives in floods in Hungary during the past decades, and damages have been primarily of economic and social nature. Therefore we focused questions on exploring such impacts.

Table 1 lists the components of exposure, vulnerability and impacts that formed the basis of the survey questions.

\footnotetext{
${ }^{1}$ Data collection was supported by the following organisations: United Nations University and the Research Institute for Soil Science and Agro-chemistry of the HAS (Bodrogköz); UNDP GEF, Directorate of the Hortobágy National Park and the Ministry of Environment (Bereg). Data processing was financed by the Department of Mathematics and Information Technology of Corvinus University.

${ }^{2}$ The data were collected from the census database (2001) of the Hungarian National Statistical Office.

${ }^{3}$ The concept of social capital includes trust, intra-community relations, and the strength of civil society and certain aspects of governance (see Putnam 1993 and Fukuyama 1995).
} 
Table 1 Exposure, Vulnerability and Impact sub-dimensions investigated

\begin{tabular}{|c|c|c|}
\hline \multirow{3}{*}{$\begin{array}{l}\text { I. } \\
\text { Exposure }\end{array}$} & & Exposure of the respondent's settlement to floods \\
\hline & & Exposure of the respondent's home to floods \\
\hline & & Personal experience concerning floods \\
\hline \multirow{12}{*}{$\begin{array}{l}\text { II. } \\
\text { Vulnerability }\end{array}$} & \multirow[t]{2}{*}{ Preparedness } & Preparedness of the respondent (and his/her family) for floods \\
\hline & & $\begin{array}{l}\text { Preparedness of different institutions (government, local government, } \\
\text { water authority, water associations) for floods }\end{array}$ \\
\hline & \multirow{3}{*}{$\begin{array}{l}\text { Physical and } \\
\text { mental health }\end{array}$} & Respondent's health status \\
\hline & & Respondent's lasting health damage or impairment \\
\hline & & Respondent's (mental) capacity of coping with problems \\
\hline & Qualification & Respondent's educational level \\
\hline & \multirow[t]{3}{*}{ Economics } & Respondent's economic activity and income \\
\hline & & Respondent's savings \\
\hline & & Respondent's opportunities for borrowing \\
\hline & \multirow[t]{3}{*}{ Social capital } & Trust in members of the community and in institutions \\
\hline & & Respondent's social relations and isolation \\
\hline & & Civic activity of respondent \\
\hline \multirow[t]{2}{*}{$\begin{array}{l}\text { III. } \\
\text { Impacts of } \\
\text { floods }\end{array}$} & & $\begin{array}{l}\text { Respondent's (and family's) damages and disadvantages caused by } \\
\text { recent floods }\end{array}$ \\
\hline & & Lasting effects of recent floods. \\
\hline
\end{tabular}

\section{Summary of Questionnaire Responses}

In the following, we summarize the results of the questionnaire responses in Bereg and Bodrogköz before turning in the next section to examining the relationships among exposure, vulnerability and impacts. We present the results of bivariate analyses in which we test the significance of correlations using Chi-square tests and ANOVA model approaches ${ }^{4}$. The purpose is to give a comparison between the two selected flood hazard prone areas and to detect differences with regards to the vulnerability dimensions.

\footnotetext{
${ }^{4}$ In the present paper those interrelationships are mentioned from which significant relationships among variables can be shown, in other words we may state on the $95 \%$ confidence level that the variables are not independent of each other.
} 


\section{Exposure}

In Bereg, the overwhelming majority of respondents regard their settlement as being either strongly or weakly exposed, and less than one tenth of the respondents believe that there is no danger of floods. Two thirds of Bodrogköz respondents regard their settlement as strongly or weakly exposed to floods, whereas one third hold that there is no such danger. Those who regard their home (weakly or strongly) exposed made up about $94 \%$ of those living in the exposed settlements of Bereg, and about $72 \%$ of those living in exposed settlements in Bodrogköz. A more detailed analysis showed that active earners and diploma-holders are over-represented among those not exposed (considering either their settlement or their home not to be exposed) in the Bodrogköz area, whereas the unemployed and people with primary education were over proportionally represented among the exposed. In the Bereg region there was no significant relationship between exposure and socio-economic variables. Inquiring if the respondents had already experienced flooding, $90 \%$ of the Bereg respondents reported living through a flood (89\% experienced the 2001 flood in this region) and 33\% had experienced multiple floods. In the Bodrogköz region $32 \%$ of the respondents had experienced flooding and $20 \%$ multiple floods. Exposed respondents were over-represented among those who had lived through at least one flood, indicating a (significant) correlation between having experienced floods and perceiving a higher exposure.

\section{Preparedness}

Tables 2 and 3 present the assessment of past and future flood preparedness among people who had experienced floods in both regions. On a five-point scale, the average assessment was between 2.07 and 3.37. Assessments of past preparedness were lower in every category than for future preparedness, and Bereg was considered better prepared than Bodrogköz. Differences, however, between values of future and past preparedness were very similar in both regions, around 0.7. As far as institutions are concerned, people regard water management authorities as the most prepared in both regions, followed by water associations and local governments. The lowest scores were given to the central government. In the Bodrogköz region the respondents assessed their own preparedness more positively than that of the central government, whereas people of Bereg regarded their own preparedness as less positive.

Table 2 Responses to question asking how prepared were respondent, repondent's family and relevant institutions for floods in the past (average of a five-grade scale)

\begin{tabular}{|l|c|c|}
\hline & Bereg & Bodrogk ̈̈z \\
\hline You and your family & 2.07 & 2.31 \\
\hline The central government & 2.42 & 2.11 \\
\hline The local government & 2.49 & 2.32 \\
\hline The water management authority & 2.59 & 2.51 \\
\hline The water associations & 2.56 & 2.35 \\
\hline
\end{tabular}


Table 3 Responses to question asking how prepared are respondent, respondent's family and relevant institutions for future floods (average of a 5-grade scale)

\begin{tabular}{|l|c|c|}
\hline & Bereg & Bodrogk ̈̈z \\
\hline You and your family & 3.0 & 3.09 \\
\hline The central government & 3.16 & 2.91 \\
\hline The local government & 3.24 & 3.16 \\
\hline The water management authority & 3.37 & 3.26 \\
\hline The water associations & 3.32 & 3.14 \\
\hline
\end{tabular}

Interestingly exposed people considered themselves better prepared than those not exposed in both regions ${ }^{5}$.

Physical and mental health

The respondents were asked to evaluate their own health status on a five-grade scale. The average assessment was 3.32 in Bereg and 3.34 in Bodrogköz. In Bereg and Bodrogköz, there were larger proportions of women, pensioners, people above 50, those with primary education, and people having low (household) income, who assessed their health status as poorer. Alternatively, men, people between the ages of 18 and 39 (18 and 49 in Bodrogköz), active earners, those who had completed their secondary studies and those who had a medium or high income were over-represented among those considering themselves to have good health status. Women reported a significantly worse health status than men. Fifty per cent of men, whereas only $38 \%$ of women regarded themselves as in good health in the Bodrogköz region, while these proportions were 55 and 41 per cent respectively in Bereg.

The respondents were also asked whether they had lasting health damage or impairment. From this question the population of Bodrogköz seems to be somewhat healthier: $28.9 \%$ reported having permanent damage to their health, as contrasted to Bereg, where this proportion was $33 \%$. In Bereg, pensioners, people with primary education and those of the lowest income indicated permanent health damage above the average. In the Bodrogköz region it was mostly pensioners, those of primary education, people above 50 and of low-medium income who indicated having lasting health damage. In Bereg as well as in Bodrogköz the relationship between health status and health damage was significantly correlated.

Another potential factor of vulnerability is the capacity to cope with problems, which we explored with a question that elicited coping strategies of those who experienced a flood. In both regions, a typical response for coping was to try to analyze and understand the situation, especially among the younger people (40-49) and those considering themselves as less exposed. In Bereg a typical coping strategy was to take a positive attitude or interpretation of the problems faced. In Bodrogköz, a frequent response was coping through positive personal change or "emerging as a different person", combined with creative activity. Taking sedatives and medicines, as well as self-destructive activities, were characteristic only to a small extent, but more in Bodrogköz than in Bereg and more by those considering themselves less healthy.

\footnotetext{
${ }^{5}$ Opinions assessing the current situation in the Bereg region are an exception where the difference is within the margin of error.
} 
Education

The proportion of respondents having completed not more than 8 classes of primary school was $59 \%$ in Bereg and $47 \%$ in the Bodrogköz region. In Bereg $21 \%$ and in Bodrogköz $31 \%$ of the respondents held certificates from a vocational secondary school. The proportion of those who had passed their grammar secondary final certificate was 14 and $18 \%$, respectively, whereas the proportion of those who had university degrees was 5 and $4 \%$, respectively.

Household economic data

As far as employment status is concerned the survey responses are reported in Table 4.

Table 4 Employment status of interviewees (\%)

\begin{tabular}{|l|c|c|}
\hline & Bereg & Bodrogköz \\
\hline Active earner & 26.3 & 23.4 \\
\hline Pensioner & 42.0 & 39.7 \\
\hline Unemployed & 15.7 & 15.4 \\
\hline Other inactive & 16.0 & 21.5 \\
\hline
\end{tabular}

The proportion of active earners is lower in both regions than the national average (58\%), and unemployment is more than double the national average $(7.5 \%)$. Responses to questions on household incomes follow a similar pattern, except the proportion of medium incomes (HUF 91$120,000)$ and high income (above HUF 121,000) are somewhat higher in Bereg (28\% and 30\%) compared to $25 \%$ and $26 \%$ percent in Bodrogköz.

Savings can enable households to recover from floods and thus represent an important factor reducing vulnerability and building coping capacity. Table 5 shows the types of reported savings.

Table 5 Reported forms of savings (\%)

\begin{tabular}{|l|c|c|}
\hline & Bereg & Bodrogköz \\
\hline In real estate & 2.3 & 7.9 \\
\hline Other assets & 11.0 & 10.8 \\
\hline At home in cash & 19.7 & 12.8 \\
\hline In savings books and savings accounts & 22.0 & 20.1 \\
\hline In life-, pension- or health insurance funds & 16.7 & 14.1 \\
\hline
\end{tabular}

Not surprising, those with primary education, the unemployed and other inactive persons are overrepresented among those not having savings, which in Bereg was $66 \%$ of the population and in Bodrogköz 57\%. In the Bodrogköz region, people living in exposed regions mentioned real estate and other assets as forms of savings in larger proportions than those in Bereg, whereas cash at home and savings accounts were mostly characteristic of pensioners. It is active earners, people with grammar, secondary school, and university degrees as well as people between 30 and 39 years of age, who invest in insurance.

As in the case with savings also borrowing capabilities can enable households to recover from floods and thus also represent an important factor. Table 6 presents the different borrowing options dependent on the amount needed. 
Table 6 Reported form of borrowing options (small and large)

\begin{tabular}{|l|c|c|c|c|}
\hline & \multicolumn{2}{|c|}{ Small Amount } & \multicolumn{2}{c|}{ Large Amount } \\
\hline & Bereg & Bodr. & Bereg & Bodr. \\
\hline From immediate family members & 74.7 & 62.6 & 13.0 & 10.3 \\
\hline From a relative living in the same settlement & 33.3 & 32.4 & 5.3 & 6.9 \\
\hline From a distant relative & 13.3 & 9.0 & 1.3 & 2.2 \\
\hline From an acquaintance, neighbour, or associate at work & 22.3 & 16.3 & 2.7 & 1.8 \\
\hline From a bank, a credit institution & 41.0 & 20.6 & 27.3 & 21.4 \\
\hline
\end{tabular}

In Bereg the possibilities of taking loans were assessed as better in every category than in the Bodrogköz region. Generally speaking the possibility of getting loans from close relatives and acquaintances occurred in greater proportion in the case of smaller sums only, whereas distant relatives did not figure significantly either in the case of smaller or of significant sums. It was active earners, those with grammar secondary education and university degree who mentioned the various possibilities of taking loans above the average. In Bereg active earners and people of at least secondary education were those who had outstanding proportions among those capable of receiving smaller loans. In addition to those groups it was mostly people of medium- and high household income and those between 40 and 49 years of age who were capable of getting bigger loans.

\section{Social capital}

Trust can be an important indicator of social capital (Simmel 1950; Newton 2001). We measured (i) trust in members of the close community (neighbours, acquaintances, associates at work) and (ii) trust in public institutions. A low level of trust was found in community members and public institutions in both regions (Table 7).

Table 7 Trust in members of the community (Averages of a hundred-grade scale)

\begin{tabular}{|l|c|c|}
\hline Trust in & Bereg & Bodrogköz \\
\hline People living in the neighbourhood and in the vicinity & 36 & 39 \\
\hline In more distant acquaintances & 40 & 40 \\
\hline In people of workplace & 45 & 45 \\
\hline
\end{tabular}

In the Bereg region, active earners were over-represented among those who trusted members of the community, whereas pensioners, the unemployed and those of the lowest income were overrepresented among the mistrustful. In the Bodrogköz region trust-related responses do not offer as uniform of a picture as in Bereg. Active earners trusted most their neighbours; pensioners trusted most their more distant acquaintances, whereas active earners, men, those of vocational secondary education and people of the highest income had greatest trust in their associates at work. The unemployed, other inactive people, as well as low-medium income people were more mistrustful of their neighbours. People between 18 and 29 years of age as well as the unemployed were mistrustful of more distant acquaintances. Women, people of primary education as well as low- and medium-income were less trustful of their associates at work. 
The most trusted institutions in both regions were the schools, police, water management authorities and water associations. The credibility of the national government was regarded the lowest in both areas. Considering the socio-demographic variables, the younger age groups, the less qualified and those of lower incomes, as well as inactive people, reported less trust in public institutions than the average. The main difference between the two regions is that opinions related to credibility are divided by age and income in the Bodrogköz region, whereas they are divided more by school education in the Bereg region. Economic activity is a significant factor in both regions.

We explored the social relations of respondents by asking how many family members and relatives lived in the given settlement or region. The average number of family members and relatives living in the same settlement was 22 in Bereg and 21 in Bodrogköz. We measured social isolation by asking how much the respondent agreed to the following statement: "I frequently feel myself lonely." In Bereg $26 \%$ of respondents reported that this statement was fully or partly true, whereas this proportion was $24 \%$ in the Bodrogköz region. In Bereg, women and pensioners were in the greatest proportion among those who feel entirely or partially lonely, whereas in the Bodrogköz region they were joined by those with low incomes and only primary education. The extent of loneliness shows negative correlation with the number of relatives in the settlement and region in Bereg as well as in the Bodrogköz region. We measured the civic activities of respondents by the question whether the interviewee had contacted the local government about an issue affecting him or her. The results are given in Table 8 .

Table 8 Have you ever tried to contact the local government about an issue that affected you? $(\%)$

\begin{tabular}{|l|c|c|}
\hline & Bereg & Bodrogköz \\
\hline Yes, once & 9.4 & 9.2 \\
\hline Yes, several times & 13.7 & 17.7 \\
\hline No & 76.9 & 73.1 \\
\hline
\end{tabular}

In the Bodrogköz region it was people in the 50 to 59 year age group and those of low to medium income who were over represented among the most active. In Bereg most frequently those between 30 to 39 years of age, diploma-holders and the unemployed had contacted the local government.

The impacts of floods

We measured the negative impacts of floods (losses, damages, indirect effects), their gravity and duration by several questions addressed to those who had experienced floods. From Table 9 it can be seen that there was a significant difference between the two regions with respect to flood damages. In Bereg the overwhelming majority of the population suffered some kind of damage, whereas that proportion was around one third in the Bodrogköz region. As far as material damages are concerned, in both regions residential property, agricultural buildings, furnishings of the home, as well as crops, arable land, vineyards and orchards suffered damages most frequently. 
Table 9 Types of flood damages suffered since 1998 among those who experienced floods (\%)

\begin{tabular}{|l|c|c|}
\hline Type of damage & Bereg & Bodrogk ̈̈z \\
\hline The settlement of residence suffered damages & 81 & 42 \\
\hline Residential home or flat damaged & 77 & 38 \\
\hline Respondent (and family) was evacuated & 74 & 9 \\
\hline Relatives suffered damages & 71 & 29 \\
\hline Agricultural buildings (e.g., pen, stable) were damaged & 57 & 22 \\
\hline Furnishings, furniture was damaged & 49 & 19 \\
\hline Crops, arable land, vineyard, orchard were damaged & 39 & 37 \\
\hline Stock and harvested grain were damaged & 28 & 7 \\
\hline Savings were reduced, spent & 23 & 16 \\
\hline Absence from work, loss of salary and income & 13 & 4 \\
\hline Illness generated or renewed by floods & 6 & 7 \\
\hline
\end{tabular}

Studying the relationships between damages, exposure, and socio-economic variables revealed some insights related to vulnerability. In Bereg, those who suffered the most damages to their homes and agricultural buildings were not only those most exposed, but there was a correlation with respondents reporting low trust in local institutions, limited savings, and limited access to even small sums of loan. In the Bodrogköz region, the correlations were similar with the exception that those most affected also considered themselves to less prepared. In both regions, floods appeared to impose more losses on those in poor health. The largest difference between the two regions was the number of those experiencing evacuations - 9\% in the Bodrogköz region compared to $75 \%$ in Bereg. Those evacuated appeared to be disproportionally in the group who were mistrustful of members of the community and public institutions, had no savings and could not obtain small loans.

Another question, reported in Table 10, asked about the duration of the physical impact of the floods. The perception of duration appears to be shorter in Bodrogköz, although it is striking that around one-fifth of those experiencing floods in the past feel that the impacts have continued to the present.

Table 10 Assessment of the durability of flood impacts among those who experienced floods $(\%)$

\begin{tabular}{|l|c|c|}
\hline Categories of answers & Bereg & Bodrogköz \\
\hline Three months & 15 & 27 \\
\hline Six months & 16 & 35 \\
\hline One year & 47 & 20 \\
\hline Still can be felt & 20 & 16 \\
\hline "There was no flood" & 2 & 2 \\
\hline
\end{tabular}

In the Bereg region this response was related to trust. Those who perceived the effects of floods for a shorter time were those who trusted their neighbours, acquaintances and associates at work, and felt most public institutions were credible.

According to the above analysis the two investigated flood basins significantly differ in terms of exposure, i.e., in Bereg a much higher proportion of homes is exposed to floods than in Bodrogköz, and similarly, a much higher proportion of the inhabitants have already experienced 
flooding and suffered damages. In terms of socio-economic characteristics differences between the two areas are smaller. Concerning the level of health, education, and savings the situation is somewhat better in Bodrogköz than in Bereg, whereas the ratio of active earners, the magnitude of household incomes and the opportunities for taking loans are somewhat more favorable in Bereg. More importantly, however, both regions are strongly handicapped if compared with the national average, especially in terms of qualification and economic activity.

\section{Vulnerability Indicators}

After the detailed presentation and comparison of the vulnerability and exposure variables for the two regions, we now turn to the question what variables or sets of variables can explain best the impact variables. As shown in Figure 1 we will treat impacts a function of exposure and vulnerability. This assumption seems to be valid as exploratory bivariate correlation analyses have shown that most impacts are related to perceived flood exposure, and to most of the hypothesized vulnerability variables, while keeping exposure constant. To identify factors, i.e. sets of variables representing a latent construct, not measurable with a single variable, we first applied principle component analysis ${ }^{6}$ of impacts by creating these variables first (see Table 11) and afterwards looked at the vulnerability and exposure variables which show significant correlation:

Table 11 Selected impact (damages and indirect effects) variables

\begin{tabular}{|l|c|}
\hline Variables & Abbreviation \\
\hline Damages in residential property and/or in its contents & D1 \\
\hline $\begin{array}{l}\text { Agricultural damages } \\
\text { (damages to agricultural buildings, crops, harvest stock) }\end{array}$ & D2 \\
\hline Loss of income & D3 \\
\hline Evacuation and/or health damage & D4 \\
\hline Duration of impacts & D5 \\
\hline
\end{tabular}

The exposure variable was chosen to be the respondents' exposure variable (a combination of the settlement' exposure and the home's exposure variables, called E1). The following vulnerability variables were selected based on (i) significant correlation to damages, and (ii) which carry the largest information content within the given group of variables. Table 12 is showing the results.

\footnotetext{
${ }^{6}$ Some variables were transformed in advance, for instance we have transformed variables measured on scales of four and five grades into a hundred-grade scale.
} 
Table 12 Vulnerability variables selected on the basis of principle component and correlation analysis

\begin{tabular}{|l|c|}
\hline Variables & Abbreviation \\
\hline Health status & V1 \\
\hline School education & V2 \\
\hline Economic activity & V3 \\
\hline Household income & V4 \\
\hline Having any form of savings & V5 \\
\hline Possibility of getting a small loan & V6 \\
\hline Possibility of getting a large loan & V7 \\
\hline Trust in members of the community & V8 \\
\hline Assessment of the credibility of institutions & V9 \\
\hline Assessment of past preparedness & V10 \\
\hline Assessment of future preparedness & V11 \\
\hline
\end{tabular}

Some interrelationships and important differences between the two regions were identified among the above variables. In Bereg significant relations exist among the V1-V7 variables. In Bodrogköz significant relations were found among the V3-V8 variables, and V1 is also correlated with variables V3, V4, V5 and V7. In Bereg the V8-V11 indices of trust and preparedness show correlation with each other, whereas in Bodrogköz they show close correlation rather with members of the V1-V8 group. There are significant connections between respondent's exposure (E1) and certain indicators of vulnerability (V1, V4 in Bereg, V2, V3 and V6 in Bodrogköz). The socio-economic status of those exposed is somewhat worse; there are greater proportions of less healthy, less qualified and less active people among them. This suggests that socially disadvantaged groups live in larger proportions in high risk areas. Respondent's exposure (E1) shows significant correlation with most indicators standing for impacts (D1-D5) in both regions. All the vulnerability indicators (V1-V11) show significant correlation to the variables indicating impacts (D1-D5) (even if the effects of exposure are screened), at least in one region.

The above analysis indicates that there are strong relations among various vulnerability indicators, as well as between variables of exposure, vulnerability, and impacts. In order to further analyze these relationships, latent factors based on the results above are constructed. However, we re-assessed the reliability of the scales too. Afterwards, we determined the set of variables for each of the factors by choosing only those variables from each set that returned the highest reliabilities (using Cronbachs Alpha). The factors that have been built with this procedure are listed in Table 13. 
Table 13 Latent Factors, number of variables

\begin{tabular}{|l|c|}
\hline Index (Abbreviation) & Number of variables used \\
\hline Impact Factor (IdF) & 11 \\
\hline $\begin{array}{l}\text { Preparedness Institutions Factor } \\
\text { (VprepF) }\end{array}$ & 4 \\
\hline Savings Factor (VsavF) & 5 \\
\hline Borrowing Factor (VborF) & 10 \\
\hline
\end{tabular}

Using the new factors, as well as the other vulnerabilities explained in detail in the previous section, we proceeded with multivariate tests and analyses. As Figure 2 indicates, it is evident that the „Area" variable (Bereg or Bodrogköz), as well as the "Exposure" variable have a dominant role for the impact factor IdF .

The IdF for each exposure sub-group is higher for the Bereg area. ${ }^{7}$ Furthermore, one can see that for decreasing exposure there is a decrease in the IdF irrespective of the Area variable. Differences between the IdF and the Area variable, as well as the Exposure variable, are highly significant. However, this is not the case for the interactions between the two variables and IdF, i.e. Area and Exposure together does not show significantly different IdF values.

8

As regards the relationships between vulnerability variables and impacts, savings and borrowing abilities (and both together) are important, e.g. the higher the capacities, the lower the impacts, however, correlations are low. Not surprisingly, perception of good self preparedness in the past correlates with lower impacts, and to the contrary, bad perception of the preparedness of the responsible institutions correlates with high impacts. Also, with higher social relationships within the community, impacts decrease. Alternatively, stronger civic activity shows higher impacts, which could be explained in the sense that those who suffer large losses have more motivation to complain to the authorities, which would then mean that civic activity should be regarded as an exposure variable. Vulnerability indicators drawn from the above analysis are summarized in Table 14.

\footnotetext{
${ }^{7}$ Which can be seen, for example, by the thick black line in each box plot which represents the median.

${ }^{8}$ As a next step, to incorporate interactions between the vulnerability and exposure variables as well as the latent factors, a general linear model approach was used. Here, combinations of factors (dichotomous variables) and covariates (continuous variables or factors) can be studied in more detail. Usually, continuous independent variables are called covariates and dichotomous independent variables are called factors in general linear models. Hence, we use these terms in the following.In more detail, a general linear model with two factors (Exposure and Area), as well as the corresponding vulnerability covariates, was created and tested. Interrelationships up to the third level were also enabled. The model was significant with an R square of 0.699. Significant variables included the Exposure and Area variables, trust, education, borrowing capacity, savings, health and perception of (past) institutional preparedness. In a next step the sample was analyzed by means of dummy variables again using a general regression model, but now without the factors, but keeping interactions possible up to the second level. For example, we looked at each Exposure and Area sub-group and performed a regression analysis. For Bodrogköz (medium exposure) no significant variables were found. Reasons for that could be the small number of observations, as well as a small spread of the IdF variable. For Bereg (high exposure) significant variables included education, savings level, borrowing capacity, trust, social relations (i.e., number of family members in the region), and civic activity.
} 
Table 14 Vulnerability variables derived from regression analysis

\begin{tabular}{|l|c|}
\hline Variables & Abbreviation \\
\hline Health status & V1 \\
\hline School education & V2 \\
\hline Savings Factor & VsavF \\
\hline Borrowing Factor & VborF \\
\hline Trust in members of the community & V8 \\
\hline Social relations & V12 \\
\hline Preparedness Institutions Factor & VprepF \\
\hline
\end{tabular}

The importances of the variables differ dependent on exposure level. Especially health status and education are important vulnerability indicators for middle exposed households, while for highly exposed households, savings, borrowing, trust, and social relations are more important as indicators for vulnerability. Trust and perception of preparedness of institutions are overall indicators of vulnerability (but with lower correlations).

\section{Conclusions and Recommendations}

The primary aim of the paper was to determine the major socio-economic factors of flood vulnerability in regions highly exposed to floods. As it was expected, the most important single variable determining impacts was the level of exposure and geographical location. Most important indicators of social vulnerability proved to be the following: health, education, savings, opportunities of taking loans, trust in the members of the community and institutions, social relations, and perception of preparedness of institutions against flood events. Remarkably, the majority of indicators are related to human and social capital, as well as institutional capacities. Economic variables, including income and employment appear less significant, which may partially be the result of the low reliability of such data.

We found that the situation of the population of the Upper Tisza regions is rather diverse regarding vulnerability. Only 40 to $50 \%$ of the population assesses their health status as being good; only 40 to $55 \%$ have completed more than primary education; only 35 to $45 \%$ have savings; and less than 35\% would have access to large loans. Trust is rather low and people assessed their flood preparedness as slightly higher than mediocre. On the basis of the survey, it is possible to identify the most vulnerable groups that are in a disadvantageous position, due to their health and education status, as well as economic strength and social relations. Hence, these indicators seem to be valid for determining the social vulnerability due to floods.

This research goes beyond the study of the vulnerability of the regions in question. Based on the indicators identified and the questionnaire created for their measurement it may be expedient to assess the vulnerability of populations in other high flood risk areas and to identify the particularly vulnerable groups. From a policy perspective, it seems worthwhile to further identify options for reducing the level of exposure, either by structural or non-structural mitigation measures. In addition, there are various opportunities to increase the resilience of exposed communities. For example, increasing public spending on education would increase the resilience of households in the future. Strengthening social cohesion would most likely be an effective intervention. From a disaster risk financing strategy, limited options remain for the 
government to directly help people at the household level. However, there are large opportunities to help the population help themselves in the future, for example, by introducing contingency loans so that borrowing is also feasible for poorer communities, by creating incentives to increase informal strategies to lessen the short term (and therefore also the long term) consequences of the disaster event, such as providing information on what should be done in case of floods (e.g. safe meeting places for inhabitants, as well as for volunteers), and by providing timely information on where to apply for financial support.

\section{References}

Alcamo J, Moreno JM, Nováky B, Bindi M, Corobov R, Devoy R.J.N, Giannakopoulos C, Martin E, Olesen JE, Shvidenko A (2007) Europe. Climate Change 2007: Impacts, Adaptation and Vulnerability. Contribution of Working Group II to the Fourth Assessment Report of the Intergovernmental Panel on Climate Change. In: Parry ML, Canziani OF, Palutikof JP, van der Linden PJ, Hanson CE (eds.) Climate change 2007: Impacts, adaptation and vulnerability. Cambridge University Press, Cambridge, UK, pp. 541-580.

Borden KA, Schmidtlein MC, Emrich ChT, Piegorsch WW, Cutter SL (2007) „Vulnerability of U.S. Cities to Environmental Hazards." Journal of Homeland Security and Emergency Management 4(2). http://www.bepress.com/jhsem/vol4/iss2/5. Accessed 1.1.2010.

Cutter SL (2005) „The Geography of Social Vulnerability: Race, Class, and Catastrophe”, in Social Science Research Council: Understanding Katrina: Perspectives from the Social Sciences, http://understandingkatrina.ssrc.org/Cutter/. Accessed 1.1.2010.

Fukuyama F (2005) Trust: The Social Virtues and the Creation of Prosperity. The Free Press, New York.

Linnerooth-Bayer J, Mechler R, Pflug G (2005) Refocusing Disaster Aid. Science 309(5737): 1044-1046.

Parry ML, Canziani OF, Palutikof J, van der Linden P, Hanson C (eds) (2007) Climate change 2007: Impacts, adaptation and vulnerability. Contribution of Working Group II to the Fourth Assessment Report of the Intergovernmental Panel on Climate Change. Cambridge University Press, Cambridge, UK.

Putnam RD (1993) Making Democracy Work: Civic Traditions in Modern Italy. Princeton University Press, Princeton

UNDP-BCPR (2005) United Nations Development Program, Bureau of Crisis Prevention and Recovery: Reducing Disaster Risk: A Challenge for Development. United Nations Development Programme, New York.

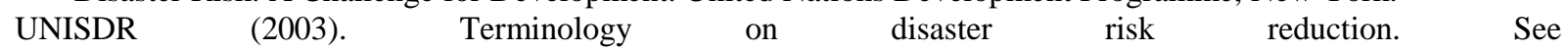
http://www.adrc.asia/publications/terminology/top.htm. Accessed 1.1.2010.

UNU-EHS (2005) United Nations University Institute for Environmental and Human Security: Vulnerability Assessment in the Context of Disaster-Risk, a Conceptual and Methodological Review. Bonn, Germany

Vári A, Ferencz Z (2006) Flood Research from a Social Perspective: The Case of the Tisza River in Hungary. In: Tchigurinskaia I, Ni Ni Thein K, Hubert P (eds) Frontiers in Flood Research. IAHS Publication 305. IAHS Press, Wallingford, UK, pp. 155-172

Walker B, Carpenter S, Anderes J, Abel N, Cumming G, Jansen M, Lebel L, Norberg J, Perereson G, Pichard R (2002) Resilience Management in Social-ecological Systems: a Working Hypothesis for a Participatory Approach. Conservation Ecology 6(1):14 